\title{
Clinical Outcomes Assessment Context of Use
}

National Cancer Institute

\section{Source}

National Cancer Institute. Clinical Outcomes Assessment Context of Use. NCI Thesaurus. Code C142434.

A description of the purpose and criteria for use of a clinical outcome assessment. 